Molecules 2001, 6, M265

\title{
3,5-Bis(trimethylsilyl)-1-methyl-4-thiophenoxypyridinium Iodide
}

\section{$\underline{\text { A.J. Kay and A.D. Woolhouse* }}$}

Industrial Research Ltd., P.O.Box 31 310, Lower Hutt, New Zealand. E-mail: t.woolhouse@irl.cri.nz Received: 8 June 2001 / Accepted: 15 December 2001 / Published: 20 December 2001<smiles>C[SiH2]c1cncc([AsH2])c1S</smiles>

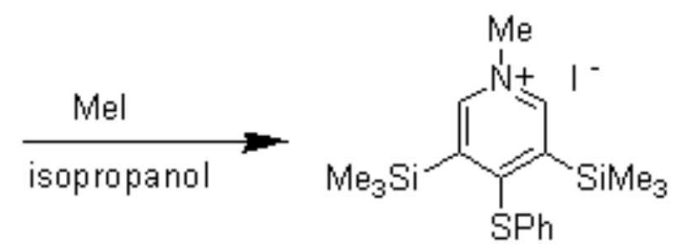

3,5-Bis(trimethylsilyl)-4-thiophenoxypyridine is readily converted to its pyridinium methiodide. The product is a precursor to "stunted" pyridylidene merocyanines that have bulky substituents at the 3-and 5-positions. Incorporation of such bulk is expected to afford chromophores with exceptionally high non-linear optical responses as a result of twisting between the donor and acceptor moieties [1].

A solution of 3,5-bis(trimethylsilyl)-4-thiophenoxypyridine [2] (1.0 g, $3.02 \mathrm{mmol})$ and methyl iodide (2.5 $\mathrm{g}, 17.6 \mathrm{mmol})$ in isopropanol $(10 \mathrm{~mL})$ was refluxed with stirring overnight, cooled and concentrated under vacuum to half its original volume. The resulting orange-yellow precipitate was recovered by filtration and washed with a little isopropanol to give a bright yellow solid $(1.18 \mathrm{~g}, 83 \%)$ that was suitable for use without further purification. An analytical sample was prepared by recrystallisation from isopropanol to give the desired pyridinium iodide as bright yellow hairs.

M.p. $259-261^{\circ} \mathrm{C}$.

${ }^{1} \mathrm{H}$ NMR (300 MHz, $d_{6}$-DMSO): 0.27, s, 18H; 4.42, s, 3H; 6.92-6.94, m, 2H; 7.20-7.25, m, 1H; 7.29-7.34, $\mathrm{m}, 2 \mathrm{H}$.

${ }^{13} \mathrm{C}$ NMR $\left(75 \mathrm{MHz}, d_{6}\right.$-DMSO): d $0.0\left(\mathrm{CH}_{3}\right), 48.2\left(\mathrm{CH}_{3}\right), 127.1(\mathrm{CH}), 127.2(\mathrm{CH}), 130.1(\mathrm{CH}), 137.5$ $\left(\mathrm{C}_{\mathrm{Q}}\right), 147.0\left(\mathrm{C}_{\mathrm{Q}}\right), 151.0(\mathrm{CH}), 163.6\left(\mathrm{C}_{\mathrm{Q}}\right)$.

Anal. Calc for $\mathrm{C}_{18} \mathrm{H}_{28} \mathrm{INSSi}_{2}$ C 45.65, H 5.96, N 2.96. Found C 45.45, H 5.89, N 2.90.

IR (nujol): 1603, 1578, 1521, 1476, 1372, 1246, 924, 846, 774.

\section{References}

1. Albert, I. D. L.; Marks, T. J.; Ratner, M. A. J. Am. Chem. Soc. 1998, 120, 11174

2. Kay, A. J.; Woolhouse, A. D. Molecules 2001, 6, M266.

Sample Availability: Available from the authors and from MDPI.

(C) 2001 MDPI, Basel, Switzerland. All rights reserved. Molecules website http://www.mdpi.org /molecules/ 